\title{
The Planetary Wave Activity in Temperatures of the Stratosphere, Mesosphere and in Critical Frequencies of Ionospheric F2 Layer
}

\author{
N. M. Polekh, G. V. Vergasova, E. S. Kazimirovsky, N. P. Perevalova, \\ V. I. Kurkin, and M. A. Chernigovskaya \\ Institute of Solar-Terrestrial Physics, SB RAS, P.O. Box 291, Irkutsk, Russia \\ Correspondence should be addressed to N. M. Polekh, polekh@iszf.irk.ru
}

Received 28 February 2011; Revised 29 April 2011; Accepted 19 May 2011

Academic Editor: Libo Liu

Copyright (c) 2011 N. M. Polekh et al. This is an open access article distributed under the Creative Commons Attribution License, which permits unrestricted use, distribution, and reproduction in any medium, provided the original work is properly cited.

\begin{abstract}
A large body of experimental evidence lends credit to the existence of a close relationship between ionospheric parameters and the underlying atmosphere. Vertical-incidence ionospheric sounding data and temperature measurements at stratospheric (30 km) and mesospheric $(80 \mathrm{~km})$ heights have been used in investigating the interrelation between the occurrence of fluctuations with periods of planetary waves in temperature variations at different heights and in F2 layer critical frequency variations (foF2) under low solar activity conditions for the time interval 2006-2007. The distinctive characteristics of the manifestation of common periodicities of the wave structures under consideration are discussed. The statistically significant periods of stratospheric and mesospheric temperature fluctuations vary from 11 to 49 days, whereas foF2 periodograms show higher-frequency fluctuations with periods of $5,8,9$, and 10 days. The study revealed a similarity between periodic structures for the variations in the parameters involved.
\end{abstract}

\section{Introduction}

Research into ionospheric variability and its causes has attracted considerable scientific and practical interest. The chief causes of the variability and the basis for its forecast are variations in the intensity of EUV radiation, solar wind, and corpuscular fluxes and magnetosphere-ionosphere coupling. It is the extraterrestrial control of the ionosphere, which is known as coming from above. In recent decades, the idea about the close relationship between ionospheric processes and processes (primarily with the dynamics) in the lower atmosphere was established and experimentally confirmed. This implies that a part of ionospheric variability is caused by atmospheric processes. It is called "effect from below" [13]. This effect occurs through the generation, propagation, and dissipation of internal atmospheric (planetary, tidal and acoustic gravity) waves. These waves, together with electric fields, can influence aeronomic processes in the thermosphere, electrodynamic drifts, and, as a result, ionospheric electron density distribution causing changes in ionospheric parameters which govern the operating conditions of radio and telecommunication HF systems $[4,5]$. Although it is well known that planetary waves are incapable of propagating directly up to the heights of the ionospheric F2 region [6], several observations of planetary wave-type oscillations (PWTOs) with periods (2-30 days) in parameters of F2region ionosphere were reported [7-12]. It was assumed that magnetic activity and variations in winds in the lower and middle thermosphere (MLT) play a key role in generation of PWTO in the ionosphere $[11,12]$. It has not yet been fully ascertained whether the PWs penetrate from the lower atmosphere using tides which readily penetrate to ionospheric heights, with their amplitude modulated by planetary waves as a carrier or, alternatively, these oscillations are generated directly within the F2 layer. Pancheva et al. [11, 13] suggested that tides modulated by the planetary waves, and particularly the semidiurnal tides which propagate freely upwards in the thermosphere, are capable to transfer the PW effect to ionospheric levels. Planetary wave signatures, with periods of approximately 16,10, and 5 days, have been observed at altitudes ranging from $30 \mathrm{~km}$ to $220 \mathrm{~km}$ over Halley $\left(76^{\circ} \mathrm{S}, 26^{\circ} \mathrm{W}\right)$, Antarctica [14]. The authors suggested there is duct of the quasi 16-day planetary wave from stratospheric midlatitudes to mesospheric high latitudes and a strong link between planetary waves in the mesosphere and F2-region. Mukhtarov et al. [15] investigated correlations: (i) between 


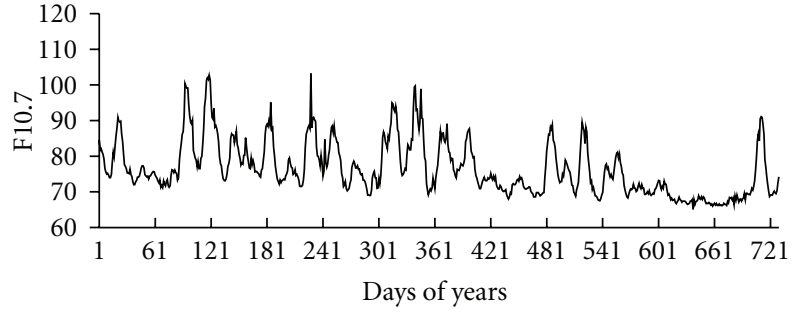

(a)

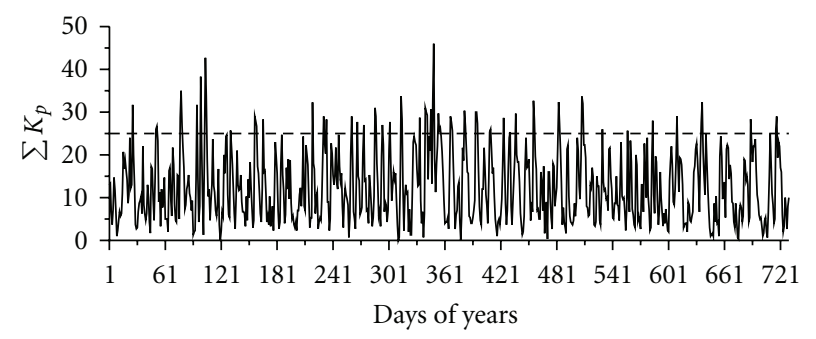

(b)

FIGURE 1: Variations of the F10.7 (a) and daily summary index of magnetic activity Kp (b) during 2006-2007. The quiet level is shown by a dotted line.

quasiperiodic variations of the sunspot numbers, solar wind, $\mathrm{Bz}$ and $\mathrm{Kp}$-index with periods of $\mathrm{PW}$ and the analogous variability in the geomagnetic field, foF2, and total electron content (TEC) and (ii) between the PWs mainly present in the temperatures $(20-120 \mathrm{~km})$ with analogous variability in the geomagnetic field, foF2, and TEC. They found that 18day wave observed in the F-region plasma (foF2, TEC) could be allocated to simultaneous 18-day planetary wave observed in the MLT region with large $(\sim 70 \mathrm{~km})$ vertical wavelength. The observed oscillations with periods $\sim 9, \sim 14$, and $\sim 24-27$ days were approved to be of solar origin.

The objective of this paper is to investigate wave structure of temperature variations at stratospheric and mesospheric heights and in variations of critical frequencies of ionospheric F2 layer (foF2) over East Siberia during the solar minimum period of 2006-2007. This period includes few solar terrestrial disturbance events which furnishes an excellent opportunity to study the influences of the processes "from below" on ionospheric electron density variations.

\section{Technique and Results}

Figure 1 shows change of the flux of a solar radio emission on a wave of $10.7 \mathrm{~cm}$ (F10.7) which is the index (proxy) of solar activity. It is evident, that F10.7 does not exceed 110 (in units $10^{-22} \mathrm{~W} /\left(\mathrm{Hz} \cdot \mathrm{M}^{2}\right)$. Figure 1 (a) plots the variations of the daily summary index of magnetic activity, Kp. The dotted line shows a quiet undisturbed level. It is possible to identify several intervals characterized by higher magnetic activity (March-April 2006 and December 2006) when moderate and stronger magnetic storms were observed. Except for these intervals, the levels of magnetic activity corresponded to quiet or weakly disturbed magnetic conditions.
For the analysis we used variations of the atmospheric temperature at heights of 30 and $80 \mathrm{~km}$ that corresponds to level of pressure $10 \mathrm{hPa}$ and $0.01 \mathrm{hPa}$, respectively. These data were obtained by means of the scanning Microwave Limb Sounder (MLS) installed aboard the EOS Aura spacecraft [16]. The Aura EOS satellite is a part of the "A-Train" mission. These satellites, intended for observation of the Earth and situated on the orbits with close parameters, make it possible to carry out unique comprehensive investigations. They fly one after another above the same regions of the Earth with an interval of $15 \mathrm{~min}$ and form the database for creation of a common image of the global climate changes. The satellites have a polar orbit (a period of rotation is about $100 \mathrm{~min}$ with a height of $705 \mathrm{~km}$ ). The spatial coverage is almost global (from $-82^{\circ}$ to $82^{\circ}$ by the latitude). Vertical profiles are measured with an interval of $\sim 25 \mathrm{~s}$ every $1.5^{\circ}(\sim 165 \mathrm{~km})$ along the orbital trajectory. About 15 flies of the satellite are carried out during a day. The MLS scans the Earth limb in the flight direction, recording the microwave emission in five spectral bands (at frequencies of 118, 190, 240, $640 \mathrm{GHz}$ and $2.5 \mathrm{THz}$ ). The data of MLS measurements are used for retrieval of profiles of the chemical composition, relative humidity, and temperature of atmospheric areas from the troposphere and stratosphere up to the upper mesosphere as functions of height of isobaric surfaces represented in hPa. The data of MLS measurements are used for retrieval of temperature profiles from the troposphere and stratosphere up to the upper mesosphere as functions of height of isobaric surfaces represented in hPa (http://disc.sci.gsfc.nasa.gov/Aura/MLS/). The effective range is from 316 to $0.001 \mathrm{hPa}$ (about 9-92 km); the accuracy in temperature measurements is $0.5-2 \mathrm{~K}$; the vertical resolution is about $3 \mathrm{~km}$. The computer code is devised, which enables obtaining the two vertical profiles of temperature over given point using input parameters: coordinates of point (latitude and longitude), distance to the satellite orbit, and local time (day or night) depending on ascending or descending satellite orbit. Analysis of the temporal and altitude temperature variations in stratosphere, and mesosphere for the Irkutsk region $\left(52^{\circ} \mathrm{N}, 104^{\circ} \mathrm{E}\right)$ over the period from August 2004 to March 2008 has been made by Chernigovskaya [17], and considerable differences of the temperature regimes in the middle atmosphere for the summer and winter seasons periods were revealed. The distribution of temperature during 2006-2007 at heights of 30 and $80 \mathrm{~km}$ over Irkutsk region is shown in Figures 2(a) and 2(b).

To study wave structure in F region we used hourly values of the critical frequencies (foF2), obtained at Irkutsk station $\left(52.5^{\circ} \mathrm{N}, 104^{\circ} \mathrm{E}\right)$ during $2006-2007$. To order to eliminate the main diurnal variation in this parameter we used deviations of observed foF 2 from sliding 27 -day median ( $\Delta$ foF 2$)$. As an example variations of $\Delta$ foF2 during 2006-2007 relating to midnight are shown in Figure 2(c).

The high-resolution spectral analysis method of the "correloperiodogram" was selected to determine the prevailing periodicities in foF2 and stratospheric and mesospheric temperatures. This algorithm devised by Kopecky and Kuklin [18] was widely used in the studies of periodic processes in atmospheric and ionospheric parameters [19-21]. The 


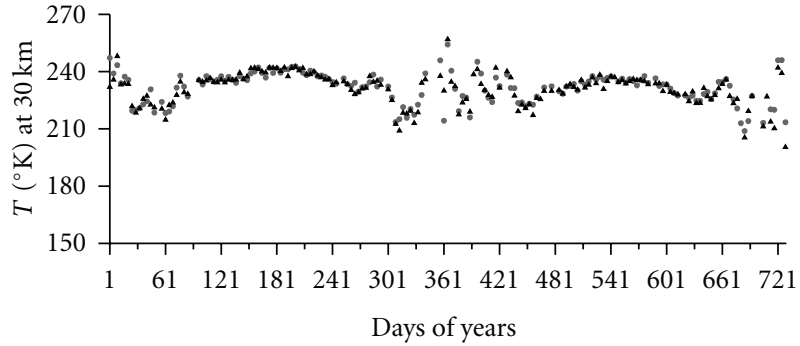

(a)

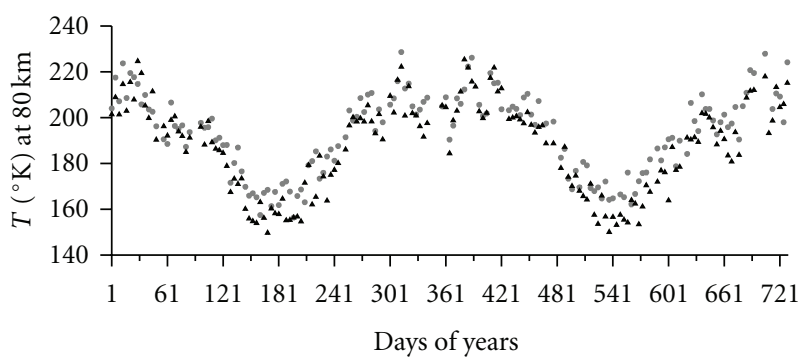

(b)

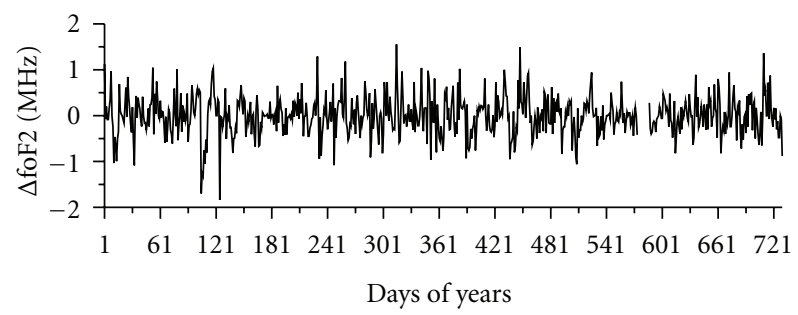

(c)

FIgure 2: The distribution of temperature during 2006-2007 at heights of $30 \mathrm{~km} \mathrm{(a)} \mathrm{and} 80 \mathrm{~km}$ (b) over Irkutsk: grey circles-day temperature, triangles-night temperature and deviations of foF2 from median, concerning local midnight (c).

validity of the resulting periodicities was verified from the 0.95 computer confidence level by using the Fisher test method.

By applying the correloperiodogram method to a 2-yearlong series of temperature variation observations, it was received that significant fluctuations with periods $>15$ days were present in stratospheric temperature variations, and there were no fluctuations with the periods $<15$ days. No statistically significant periods of fluctuations were revealed in mesospheric temperature variations for the interval concerned. It does not mean that the fluctuations with periods of planetary waves may not exist in mesosphere. As shown in $[14,22]$, waves with periods of 5-20 days must exist in the mesosphere, but their amplitudes must be small compared to the long-period waves, and therefore their amplitudes are not significant. As far as the foF2 variations are concerned, periodic structure is clearly pronounced: fluctuations with statistically significant periods of $2,3,5,9,14,16-17,18-19$, 22-23, 24-25, 28-29, and of more than 30 days were revealed.

Subsequently, in examining the seasonal features of the occurrence of fluctuations with periods of planetary waves

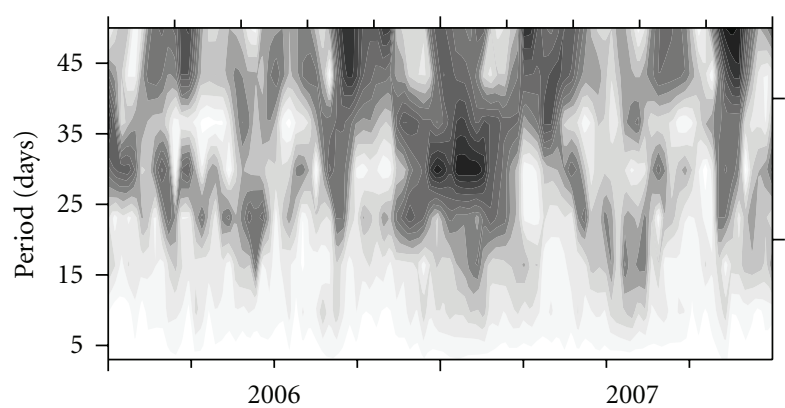

(a)

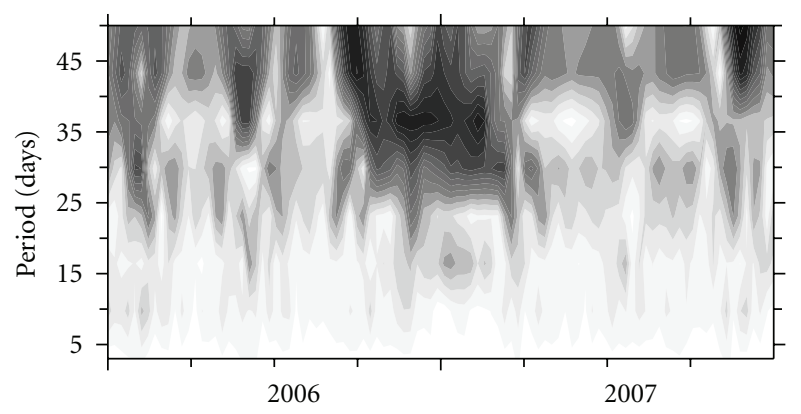

(b)

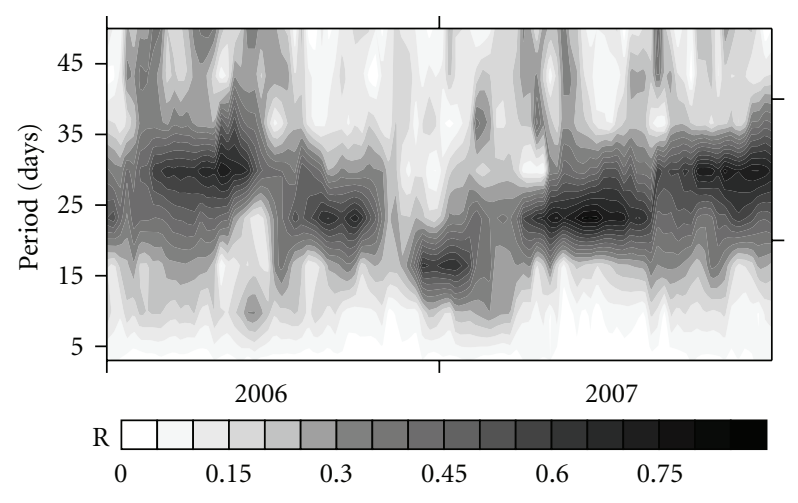

(c)

FIGURE 3: Periodogram spectra of stratospheric temperature (a), mesospheric temperature (b), $\Delta$ foF2 (c) in the period range of 550 days. Statistical significance level corresponds to $R \geq 0.3$.

we used a so-called "dynamic correloperiodogram method" $[19,20]$. We generated time series of the same length corresponding to the midday and midnight hours. Using the "time window" involving 90 values (three months) with a subsequent step of sliding equal to 5 days, we calculated the periodograms. Thus 637 periodograms were obtained for each parameter. Figure 3 provides the results from such a dynamic periodogram analysis that was applied to time series of stratospheric and mesospheric temperatures and to deviations of critical frequencies corresponding to the midnight hours. The statistically significant periods of 11 to 49 days were detected. The comparison to results in Figure 3 points out a difference between the characteristics of PWTO in the ionosphere, the mesosphere, and the stratosphere. As can be seen, in the stratosphere and the mesosphere the 


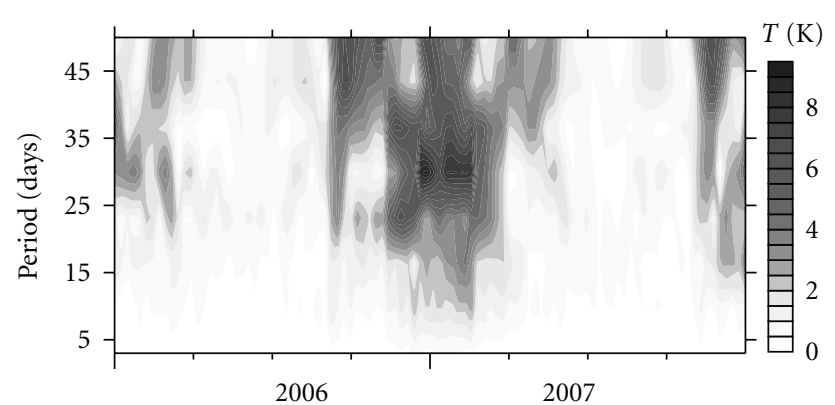

(a)

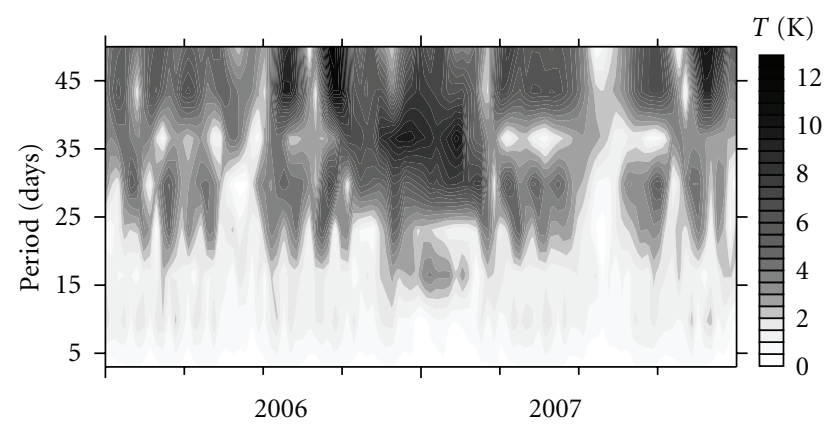

(b)

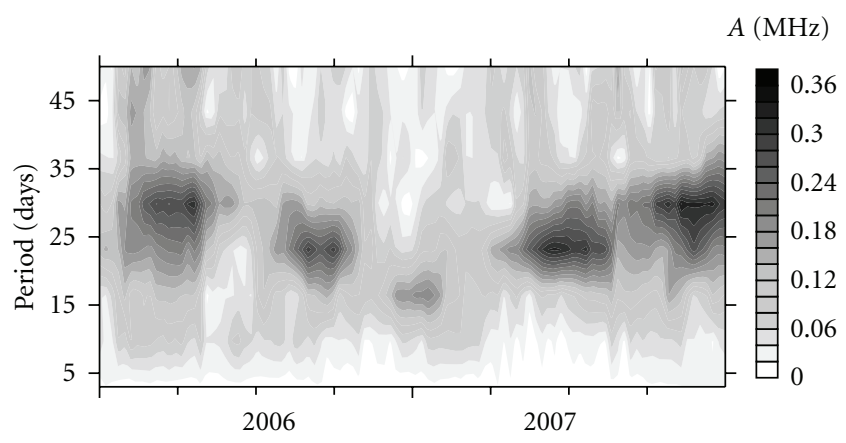

(c)

Figure 4: Amplitude spectra, calculated in period range of 5-50 days for stratospheric temperature (a), mesospheric temperature (b), and $\Delta$ foF2 (c).

strongest wave activity occurs in the wintertime and has periods above 25 days and more, while the strongest wave in foF 2 variations has periods of $8-27$ days.

Figure 4 shows the oscillation amplitude with periods of planetary waves in stratospheric and mesospheric temperature and foF 2 variations. Maximum values of PWTO amplitudes in stratospheric temperature variations are observed in the winter. With the increasing oscillation period, the amplitude increases to reach $7-8 \mathrm{~K}$ in fluctuations with periods of 25-30 days. Maximum fluctuation amplitudes in mesospheric temperature variations are observed in oscillations with periods of 40-44 days in the spring and autumn and in oscillations with periods of 25-35 days in the winter. The largest PWTO amplitudes in foF2 variations were recorded during equinoxes.

For all years considered it was determined the number of days during which the oscillations were detected. Figure 5

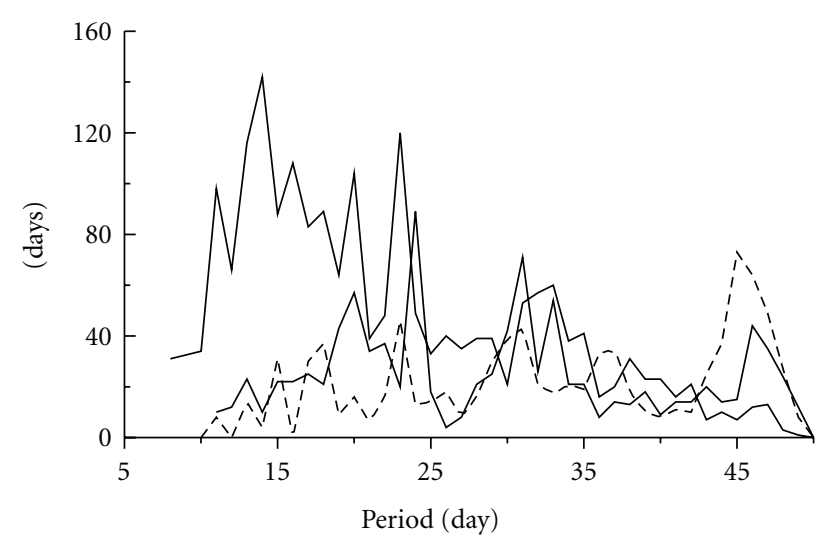

FIGURE 5: The occurrence of the wave oscillation with various periods in the temperature and $\Delta$ foF2 during 2006-2007: thick line- $\Delta \mathrm{foF} 2$; thin line-the stratospheric temperature, dotted line-the mesospheric temperature.

demonstrates the occurrence of wave oscillations of each period. Four groups of fluctuations can be identified, namely, 16-day fluctuations (periods ranging from 13 to 19 days), 24-day fluctuations (periods ranging from 20 to 28 days), 33-day fluctuations (periods ranging from 29 to 35 days), and 43-day fluctuations (periods ranging from 40 to 47 days). It can be identified the separate group of 10-day oscillations (covering a range of periods from 8 to 12 days) in foF2 variations. Fluctuations of the first and the second groups occur more often in stratospheric temperature and, especially, foF2 variations than do the others. But they are rather uncommon in mesospheric temperature variations. Fluctuations of the fourth group with periods $>40$ days are dominant in mesospheric temperature variations.

In order to study the occurrence of wave oscillation of different groups, the probability of finding an oscillation of these groups for a given month has been calculated as the number of the oscillations found for corresponding month, during two years considered, averaged by the total number of these oscillations of the corresponding months of available data. Figure 6 illustrates seasonal dependency of probability of wave occurrence in parameters under consideration. The 16-day oscillations have maximum occurrence during the first half of year in stratospheric temperature variation, and in variations of mesospheric temperature during autumn: winter, while during other months their activity is small or almost disappears (e.g., in variations of mesospheric temperature). This result is a good agreement with those obtained previously [21]. There is no marked strong seasonal dependence in foF2 variations the PWTO of 16-day period. There is a trend towards increased wave activity during summer [22]. The planetary wave type oscillation of 24-day period is predominant during summer in variations of mesospheric temperature. In variations of stratospheric temperature and foF2 this wave appears during almost the entire year.

As for the oscillations with a period of 33 days, they appear almost the entire year: in the mesospheric temperature, these waves often appear during the winter and spring, in foF2 variations they occur during equinox, and in 


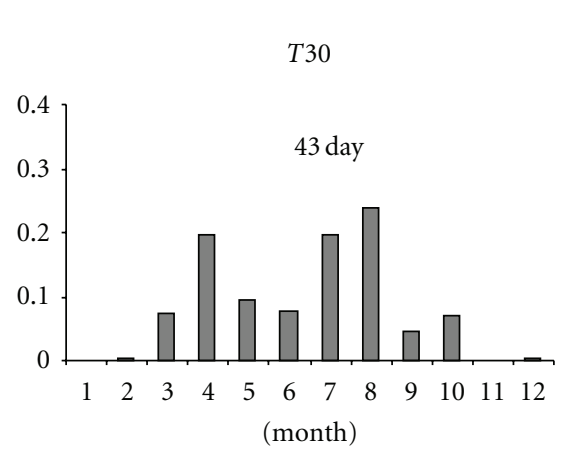

$T 80$

$\Delta$ foF2
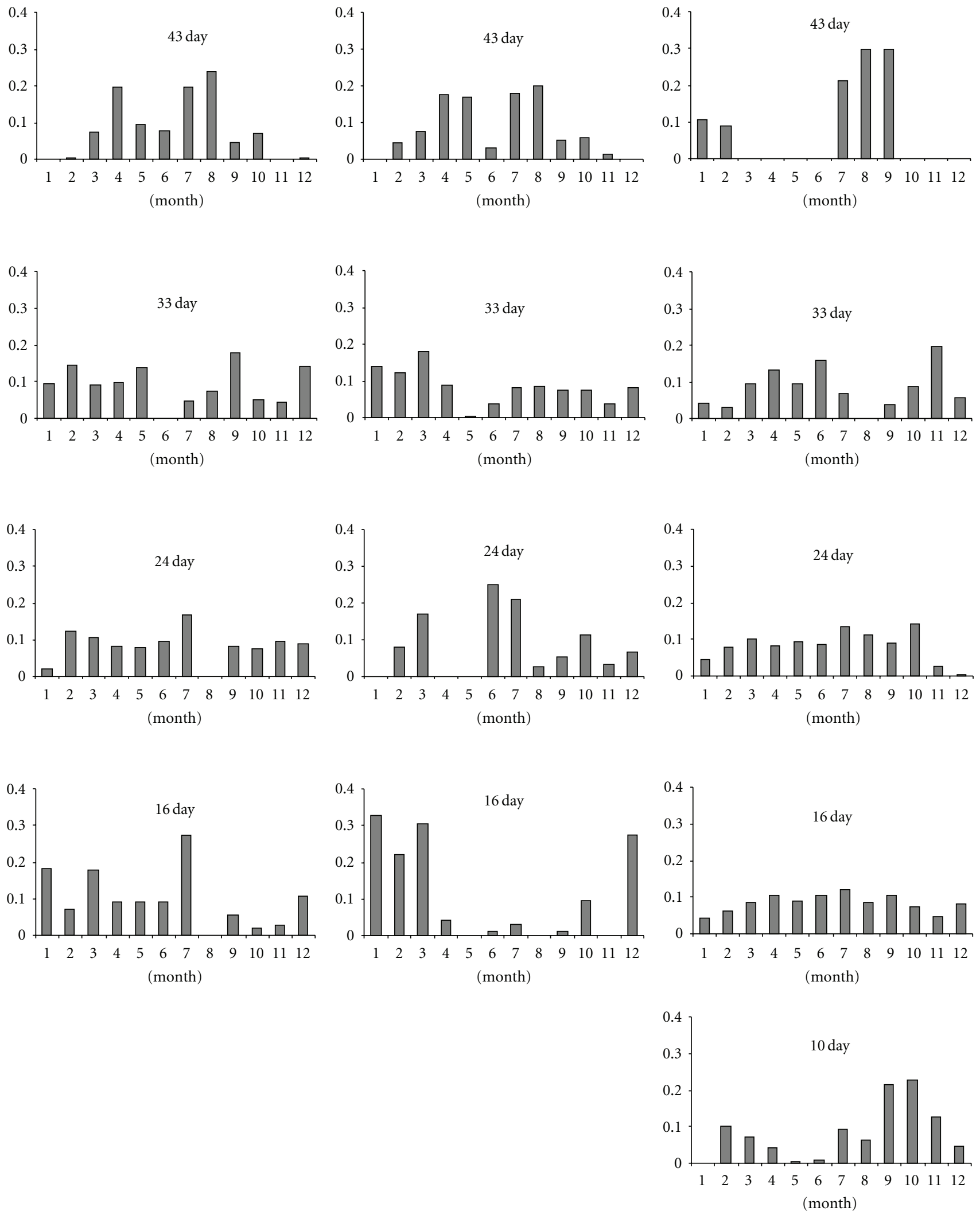

FigURE 6: The seasonal dependence of the probability of wave occurrence: T30-in the stratospheric temperature, T80-in mesospheric temperature, $\Delta \mathrm{foF} 2$-in critical frequency deviations. 
TABLE 1: Correlation coefficients between occurring oscillations with periods of planetary waves in variation of the temperature parameters and the ionospheric parameter for some periods.

\begin{tabular}{lccc}
\hline 16-day period & 24-day period & 33-day period & 43-day period \\
\hline$K_{1,2}=0.39$ & $K_{1,2}=0.59$ & $K_{1,2}=0.17$ & $K_{1,2}=0.918$ \\
$K_{1,3}=0.266$ & $K_{1,3}=0.166$ & $K_{1,3}=-0.54$ & $K_{1,3}=0.39$ \\
$K_{2,3}=-0.475$ & $K_{2,3}=0.398$ & $K_{2,3}=-0.41$ & $K_{2,3}=0.34$ \\
\hline
\end{tabular}

The first parameter: the stratospheric temperature at $30 \mathrm{~km}$; the second parameter: the mesospheric temperature at $80 \mathrm{~km}$; the third parameter: the deviations of foF2.

variations of stratospheric temperature their wave activity is maximal during autumn equinox.

The seasonal dependence of occurrence of oscillations with periods more than 40 day shows semiannual structure the most pronounced in variations foF2.

It should be remarked that there is the seasonal dependence of occurrence of oscillations with period of 10 days in foF2 variation. These oscillations seem to be present mainly during both equinoxes, specially during autumn equinox.

For each of the selected groups of oscillations, we calculated the correlation coefficients between the number of days of fluctuations occurrence during the year by months in the variations of stratospheric temperatures with analogous variations in mesospheric temperature and in foF2 with regard to the $>0.90$ confidence level by the Fisher criterion (Table 1).

It was seen that for 24-day and 43-day periods of PWTO a statistically significant correlation between the occurring oscillations in the stratospheric and mesospheric temperature variations was found. In addition, we obtained a weak correlation between fluctuations with a period of 18-19 days in the stratosphere with the 17-18 days fluctuations of the electron density $(r=0.598)$. It indicates a few similarities of wave structures revealed in stratosphere, mesosphere, and ionosphere. The major similarity is the existence of the wave activity in the stratosphere, the mesosphere, and the ionosphere during winter. As shown in [8], 50\% of PWTO intensity in the F2 layer ionosphere occurs due to solar variability. Prominent variations of the solar origin occur with about 27-28 days which is approximately the solar rotation period and its subharmonics. It is possible that in the winter this wave activity in F2 layer ionosphere may be enhanced by the forcing upward propagating 18-day wave with large vertical wavelength $[15,22]$. But the solar influence may not only produce a positive correlation between solar parameters and ionospheric characteristics. Changes in the wind system due to solar-induced changes in temperature and pressure lead to changes in mass transport that can cause negative correlation. Because of this, the question of atmosphereionosphere coupling by PW remains open. The complexity of the possible relationships between the middle and lower atmospheric parameters and the ionospheric characteristics dictates a need for further investigation under national and international programs using multidisciplinary approach, based on continuous coordinated observations in order to test the hypothesis that the planetary waves in the stratosphere and mesosphere have influence on the ionosphere.

\section{Summary}

The activity of the planetary wave-type oscillations in the stratosphere, mesosphere, and ionosphere has been studied using temperature variations at $30 \mathrm{~km}, 80 \mathrm{~km}$ heights and F2-layer critical frequency variations (foF 2$)$ at Irkutsk $\left(52^{\circ} \mathrm{N}\right.$, $104^{\circ} \mathrm{E}$ ) under low solar activity conditions for the time interval 2006-2007. The spectral analysis of the wave structure in the stratospheric and mesospheric temperature variations and in the foF2 variations has revealed the existence of fluctuations with periods of planetary waves, having different amplitude characteristics. These oscillations have periods typical for planetary waves and their wave activity is the strongest during winter. There is a considerable difference: in the ionosphere the dominant periods are shorter than the typical periods of planetary waves in the stratosphere and the mesosphere.

In the stratosphere the maximum fluctuation amplitudes are observed in oscillations with periods of 20-30 days during winter. In the mesosphere maximum amplitudes are detected in oscillations with periods of 30-35 days during winter and autumn the and in oscillations with periods of 25-45 days in the winter. The largest PWTO amplitudes in foF2 variations were recorded during equinoxes.

A statistically significant correlation between the occurring oscillations with the 40 days in the stratospheric and the mesospheric temperature variations and between the occurring oscillations with the period of 18 days in the stratospheric temperature variations and in the variations of foF2 was founded.

The obtained results are in agreement with those obtained previously by other researches and provide additional information on oscillations with periods of planetary waves in the stratosphere, the mesosphere, and the ionosphere over Eastern Siberia.

\section{Acknowledgments}

This work was supported by the Ministry of Education and Science of the Russian Federation (Project no. 14.740. 11.0078) and the Russian Foundation for Basic Research (Grant no. 11-05-00892-a).

\section{References}

[1] E. S. Kazimirovsky, "Coupling from below as a source of ionospheric variability: a review," Annals of Geophysics, vol. 45, no. 1, pp. 1-29, 2002. 
[2] E. Kazimirovsky, M. Herraiz, and B. A. de la Morena, "Effects on the ionosphere due to phenomena occurring below it: a review," Surveys in Geophysics, vol. 24, no. 2, pp. 139-184, 2003.

[3] J. Laštovička, "Forcing of the ionosphere by waves from below," Journal of Atmospheric and Solar-Terrestrial Physics, vol. 68, no. 3-5, pp. 479-497, 2006.

[4] J. Laštovička, V. Fišer, and D. Pancheva, "Long-term trends in planetary wave activity (2-15 days) at $80-100 \mathrm{~km}$ inferred from radio wave absorption," Journal of Atmospheric and Terrestrial Physics, vol. 56, no. 8, pp. 893-899, 1994.

[5] H. Rishbeth, "F-region links with the lower atmosphere?" Journal of Atmospheric and Solar-Terrestrial Physics, vol. 68, no. 3-5, pp. 469-478, 2006.

[6] A. I. Pogoreltsev, A. A. Vlasov, K. Fröhlich, and C. Jacob, "Planetary waves in coupling the lower and upper atmosphere," Journal of Atmospheric and Solar-Terrestrial Physics, vol. 69, no. 17-18, pp. 2083-2101, 2007.

[7] E. M. Apostolov, D. Altadill, and R. Hanbaba, "Spectral energy contributions of quasi-periodic oscillations (2-35 days) to the variability of the foF2," Annales Geophysicae, vol. 16, no. 2, pp. 168-175, 1998.

[8] J. Laštovička, P. Križan, P. Šauli, and D. Novotná, "Persistence of the planetary wave type oscillations in foF2 over Europe," Annales Geophysicae, vol. 21, no. 7, pp. 1543-1552, 2003.

[9] C. Borries and P. Hoffmann, "Characteristics of F2-layer planetary wave-type oscillations in northern middle and high latitudes during 2002 to 2008," Journal of Geophysical Research, vol. 115, no. 11, Article ID A00G10, 2010.

[10] M. A. Abdu, T. K. Ramkumar, I. S. Batista et al., "Planetary wave signatures in the equatorial atmosphere-ionosphere system, and mesosphere- E- and F-region coupling," Journal of Atmospheric and Solar-Terrestrial Physics, vol. 68, no. 3-5, pp. 509-522, 2006.

[11] D. Pancheva, N. Mitchell, R. R. Clark, J. Drobjeva, and J. Lastovicka, "Variability in the maximum height of the ionospheric F2-layer over Millstone Hill (September 1998March 2000); influence from below and above," Annales Geophysicae, vol. 20, no. 11, pp. 1807-1819, 2002.

[12] J. Xiong, W. Wan, B. Ning, L. Liu, and Y. Gao, "Planetary wave-type oscillations in the ionosphere and their relationship to mesospheric/lower thermospheric and geomagnetic disturbances at Wuhan $\left(30.6^{\circ} \mathrm{N}, 114.5^{\circ} \mathrm{E}\right)$," Journal of Atmospheric and Solar-Terrestrial Physics, vol. 68, no. 3-5, pp. 498-508, 2006.

[13] D. V. Pancheva, P. J. Mukhtarov, M. G. Shepherd et al., "Twoday wave coupling of the low-latitude atmosphere-ionosphere system," Journal of Geophysical Research, vol. 111, no. 7, Article ID A07313, 2006.

[14] A. R. Lawrence and M. J. Jarvis, "Initial comparisons of planetary waves in the stratosphere, mesosphere and ionosphere over Antarctica," Geophysical Research Letters, vol. 28, no. 2, pp. 203-206, 2001.

[15] P. Mukhtarov, D. Andonov, C. Borries, D. Pancheva, and N. Jakowski, "Forcing of the ionosphere from above and below during the Arctic winter of 2005/2006," Journal of Atmospheric and Solar-Terrestrial Physics, vol. 72, no. 2-3, pp. 193-205, 2010.

[16] M. J. Schwartz, A. Lambert, G. L. Manney et al., "Validation of the Aura Microwave Limb Sounder temperature and geopotential height measurements," Journal of Geophysical Research, vol. 113, Article ID D15S11, 2008.

[17] M. A. Chernigovskaya, "Morphological features of the atmosphere temperature regime in the south region of East
Siberia," in Proceedings of the 15th International Symposium on Atmospheric and Ocean Optics/Atmospheric Physics, vol. 7296 of Proceedings of SPIE, 2008.

[18] M. Kopecky and G. V. Kuklin, "About the 11-year variations of the mean life duration of a group sun spots," Issledovaniia Geomagnetizmu Aeronomii i Fizike Solntsa, vol. 2, pp. 167-175, 1971 (Russian).

[19] C. Haldoupis, D. Pancheva, and N. J. Mitchell, "A study of tidal and planetary wave periodicities present in midlatitude sporadic E layers," Journal of Geophysical Research, vol. 109, no. 2, Article ID A02302, 2004.

[20] V. D. Kokourov, G. V. Vergasova, and E. S. Kazimirovsky, "Oscillations with planetary wave periods in variations in the ionospheric parameters over Irkutsk," Geomagnetism and Aeronomy, vol. 49, no. 7, pp. 172-179, 2009.

[21] G. V. Vergasova, E. S. Kazimirovsky, and N. M. Polekh, "Relation of long-period variations in the critical frequencies of the F2 layer to geomagnetic activity," Geomagnetism and Aeronomy, vol. 49, no. 1, pp. 63-69, 2009.

[22] M. J. Lopez-Gonzalez, E. Rogriguez, Garcia-Comas et al., "Climatology of planetary wave oscillations with periods of 220 days derived from $\mathrm{O}_{2}$ atmospheric and $\mathrm{OH}(6-2)$ airglow observations at mid-latitude with SATI," Annales Geophysics, vol. 27, pp. 3645-3662, 2009. 

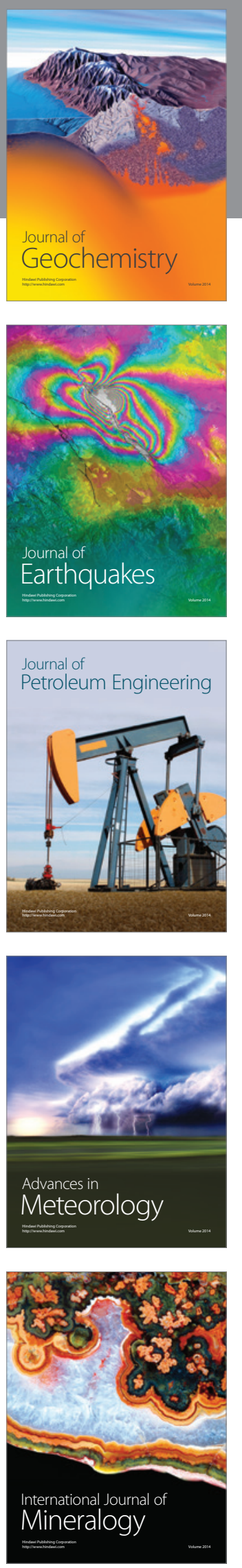
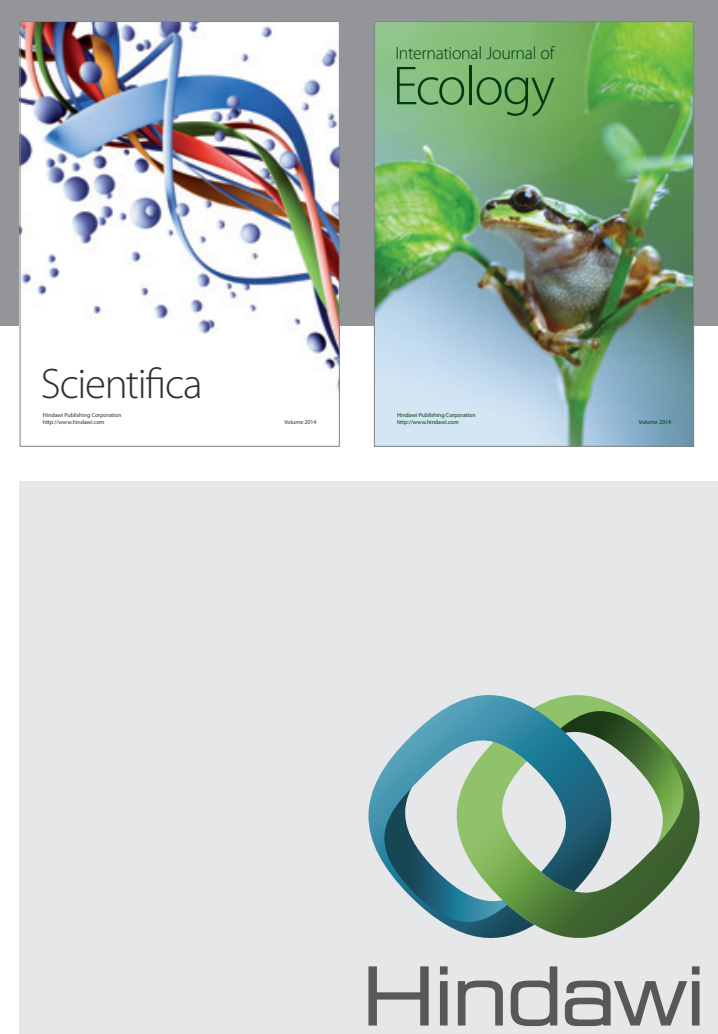

Submit your manuscripts at http://www.hindawi.com
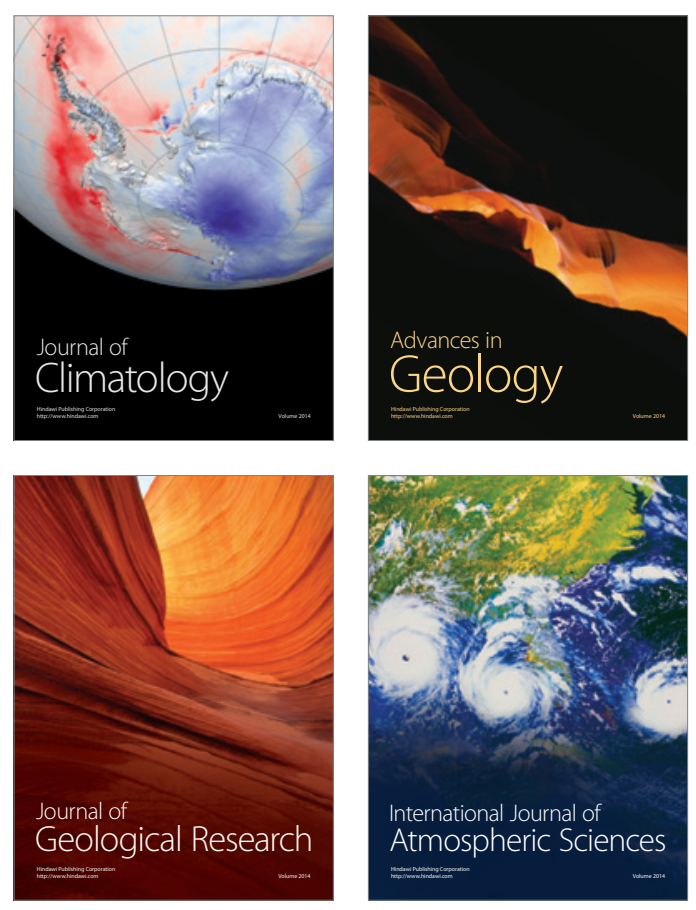
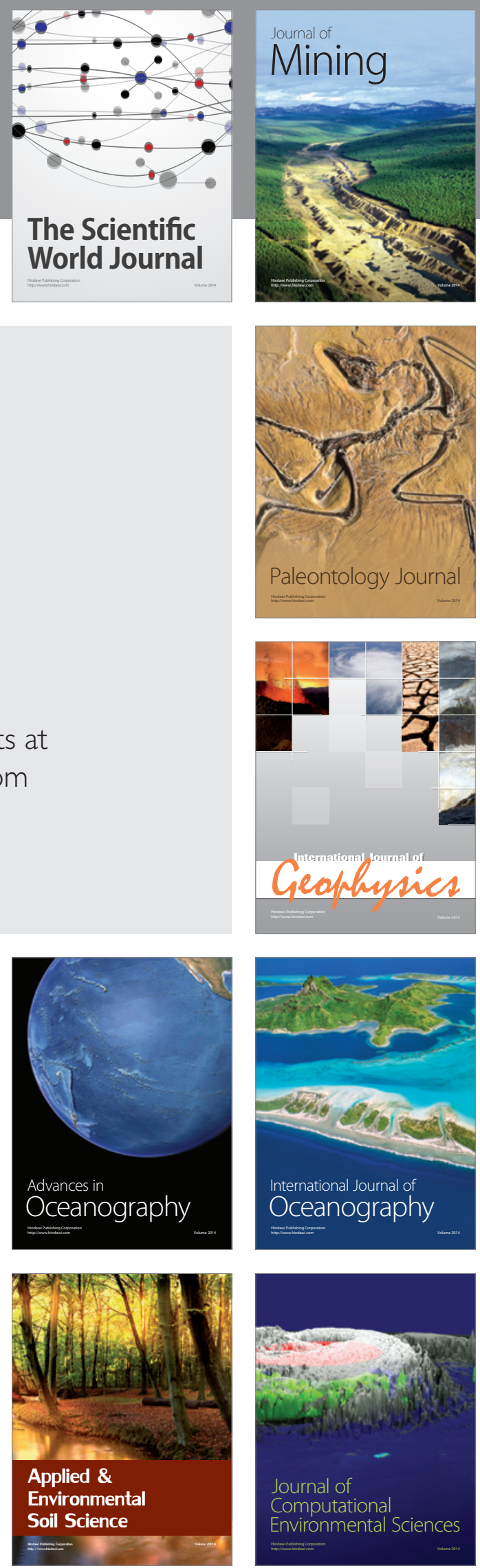